\title{
AUDIT and AUDIT-C as screening instruments for alcohol problem use in adolescents
}

\section{Liskola, Joni}

2018-07-01

Liskola , J , Haravuori , H , Lindberg , N , Niemelä , S, Karlsson , L , Kiviruusu, O \& Marttunen, M 2018 , ' AUDIT and AUDIT-C as screening instruments for alcohol problem use in adolescents ' , Drug and Alcohol Dependence , vol. 188 , pp. 266-273 . https://doi.org/10.1016/j.drugalcdep.2

http://hdl.handle.net/10138/303666

https://doi.org/10.1016/j.drugalcdep.2018.04.015

publishedVersion

Downloaded from Helda, University of Helsinki institutional repository.

This is an electronic reprint of the original article.

This reprint may differ from the original in pagination and typographic detail.

Please cite the original version. 
Full length article

\title{
AUDIT and AUDIT-C as screening instruments for alcohol problem use in adolescents
}

\author{
Joni Liskola ${ }^{\mathrm{a}, \mathrm{b}, *}$, Henna Haravuori ${ }^{\mathrm{b}, \mathrm{c}}$, Nina Lindberg ${ }^{\mathrm{a}}$, Solja Niemelä, ${ }^{\mathrm{d}, \mathrm{e}}$, Linnea Karlsson ${ }^{\mathrm{f}}$, \\ Olli Kiviruusu ${ }^{b}$, Mauri Marttunen ${ }^{c}$
}

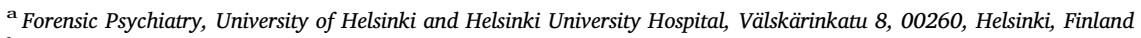

${ }^{\mathrm{b}}$ National Institute for Health and Welfare, Mental Health Unit, Mannerheimintie 160, 00300, Helsinki, Finland

${ }^{c}$ Adolescent Psychiatry, University of Helsinki and Helsinki University Hospital, Välskärinkatu 12, 00260, Helsinki, Finland

d Department of Neurosciences, University of Oulu, Pentti Kaiteran katu 1, PL 8000, Oulu, Finland

e Department of Psychiatry, Lapland Hospital District, Totontie 9, 97140, Muurala, Finland

${ }^{\mathrm{f}}$ Department of Child Psychiatry, University of Turku and Turku University Hospital, Kiinamyllynkatu 4-8, 20520, Turku, Finland

\section{A R T I C L E I N F O}

\section{Keywords:}

Adolescents

Alcohol

AUDIT

Screening

\begin{abstract}
A B S T R A C T
Background: The Alcohol Use Disorders Identification Test (AUDIT) is commonly used in adults to screen for harmful alcohol consumption but few studies exist on its use among adolescents. Our aim was to validate the AUDIT and its derivative consumption questionnaire (AUDIT-C) as screening instruments for the detection of problem use of alcohol in adolescents.

Methods: 621 adolescents (age-range, 12-19 years) were drawn from clinical and population samples who completed the AUDIT questionnaire. Psychiatric diagnoses were assessed using K-SADS-PL. A rating based on the K-SADS-PL was used to assess alcohol use habits, alcohol use disorders, screening and symptom criteria questions. Screening performance of the AUDIT and AUDIT-C sum scores and Receiver Operating Characteristic (ROC) curves were calculated. The diagnostic odds ratios (dOR) were calculated to express the overall discrimination between cut-offs.

Results: Comparisons of ROC between the AUDIT and AUDIT-C pairs indicated a slightly better test performance by AUDIT for the whole sample and in a proportion of the subsamples. Optimal cut-off value for the AUDIT was $\geq 5$ (sensitivity 0.931 , specificity 0.772 , dOR 45.22 ; 95\% CI: $24.72-83.57$ ) for detecting alcohol problem use. The corresponding optimal cut-off value for the AUDIT-C was $\geq 3$ in detecting alcohol problem use (sensitivity 0.952, specificity 0.663, dOR 39.31; 95\% CI: 19.46-78.97). Agreement between the AUDIT and AUDIT-C using these cut-off scores was high at $91.9 \%$.

Conclusions: Our results for the cut-off scores for the early detection of alcohol problem use in adolescents are $\geq 5$ for AUDIT, and $\geq 3$ for AUDIT-C.
\end{abstract}

\section{Introduction}

Alcohol is commonly consumed by adolescents in Western countries even though protective age restrictions are enforced. The use of alcohol increases during adolescence and usually progresses from experimentation to regular use (Costello et al., 2007; Masten et al., 2008). Exposure to alcohol may disturb complex biological (brain), psychological (cognitions and emotions) and normal social development in adolescents and young adults. Adverse short-term and long-term effects of alcohol differ according to age and developmental level (Zeigler et al., 2005; Masten et al., 2008). Early alcohol use is also associated with higher risk for future development of alcohol abuse, dependence, illicit drug use, and tobacco use (Dawson et al., 2008; Winters and Lee, 2008; Hingson and Zha, 2009; American Academy of Pediatrics, Committee of Substance Abuse, 2010).

The European School Survey Project on Alcohol and Other Drugs (ESPAD) in 2015 conducted among 15- to 16-year-old students in 36 European countries showed that the overall alcohol consumption among adolescents has decreased. The percentage of sober teenagers, meaning those who do not consume alcohol at all, has increased since 1999 from $10 \%$ to $26 \%$ in 2015 . Heavy episodic drinking, indicated by having 10 or more drinks on one occasion in the previous 30 days, has decreased to $15 \%$ for boys and to $9 \%$ for girls compared to previous ESPAD studies. In Finland, other time-trend studies show the decrease

\footnotetext{
* Corresponding author at: Forensic Psychiatry, University of Helsinki and Helsinki University Hospital, Välskärinkatu 8, 00260, Helsinki, Finland.

E-mail address: joni.liskola@hus.fi (J. Liskola).
} 
of drinking until drunk among 14- and 16-year-old adolescents since the late 1990s (Lintonen et al., 2013). Boys tend to consume higher amounts of alcohol on average than girls and heavy episodic drinking has been more common among them.

It has been advocated that any drinking by early adolescents, and hazardous, at-risk or binge drinking by middle adolescents should be screened for brief preventive interventions, whereas adolescents suffering from alcohol use disorders (AUDs) should be referred to appropriate treatments such as more intense or longer-term treatments (Harris and Knight, 2014; Hingson and Compton, 2014; Patton et al., 2014). Screening measures and interventions for adolescents should be feasible, acceptable and developmentally appropriate (Pilowsky and Wu, 2013; Patton et al., 2014).

The Alcohol Use Disorders Identification Test (AUDIT), a 10-item self-report questionnaire, was developed for screening harmful alcohol consumption, and alcohol-related problems in primary care (Saunders et al., 1993). The purpose of AUDIT was to enable provision of early and effective interventions (Saunders et al., 1993). The AUDIT has proved to be a valid screening tool for alcohol problems among adults in various settings (Reinert and Allen, 2002). However, the 10-item AUDIT has been argued to be too long for busy clinical settings and consequently abbreviated versions have been developed. The AUDITconsumption (AUDIT-C) contains the first three questions from the original AUDIT, which estimate the hazardous alcohol consumption factor (Bush et al., 1998; Doyle et al., 2007). Performance of the AUDIT$\mathrm{C}$ is approximately equal to that of the 10 -item version among adults (Kriston et al., 2008; Meneses-Gaya et al., 2010; Reinert and Allen, 2007). Different AUDIT and AUDIT-C cut-off scores have been suggested for hazardous or at-risk use and AUDs and for specific populations. For example, lower cut-off scores are often suggested for females compared to males (Aalto et al., 2009; Foxcroft et al., 2015; Patton and Boniface, 2016).

Comorbidity of AUDs with other mental disorders is common (Pirkola et al., 2000). Validity studies of the AUDIT and AUDIT-C among psychiatric patients have indicated mostly acceptable screening properties for alcohol problems (Boschloo et al., 2010; Dawson et al., 2005; Reinert and Allen, 2007). Alcohol use in adolescence is associated with disruptive disorders, poor impulse-control, and conduct disorders but also with depression and depressive symptoms (Masten et al., 2008). Early-onset depression predicts later frequent alcohol use in adolescents, although this association is complex in nature (Sihvola et al., 2008).

Studies on the psychometric properties and screening performance of the AUDIT and AUDIT-C in youths have been performed mainly among college and university students (Aertgeerts et al., 2000; Adewuya, 2005; Cook et al., 2005; Bowring et al., 2013; Palma et al.,
2013; García Carretero et al., 2016). Screening and performance studies have also been done in other types of settings including online screening (O'Hare and Sherrer, 1999; Kelly et al., 2004; Kokotailo et al., 2004; Thomas and McCambridge, 2008; Kelly et al., 2009; McCambridge and Thomas, 2009; Demartini and Carey, 2012; Kwon et al., 2013).

There are also studies on the psychometric properties and utility of the AUDIT and AUDIT-C in screening of alcohol problems in adolescent populations (Chung et al., 2000; Chung et al., 2002; Kelly et al., 2002; Knight et al., 2003; Kelly et al., 2004; Fairlie et al., 2006; Santis et al., 2009; Rumpf et al., 2013; Cortes-Tomas et al., 2016). The sensitivities vary from 0.65 to 0.96 and specificities from 0.63 to 0.85 on these studies in detecting problematic alcohol use. Receiver operating characteristic (ROC) curves and associated area under the curve (AUC) values for problematic alcohol use were from 0.85 to 0.93 . Santis et al. (2009) also studied the internal consistency of the AUDIT and found that AUDIT's Cronbach's $\alpha$ was 0.83 . The same studies report cut-off scores for hazardous or any problem use with the AUDIT that vary from 2 to 3 for binge drinking with AUDIT-4 (combination of AUDIT-C including the tenth question of the full AUDIT) and also with the AUDIT-3 (contains only question three). Suggested cut-off scores for the diagnosed AUDs vary from 3 to 10 for AUDIT and from 3 to 6 for AUDIT-C.

There is lack of studies on the associations of sex, age and psychiatric comorbidity on screening performance and preferred cut-off scores of the AUDIT and AUDIT-C in adolescents. The principal aim of this study was to evaluate the validity of these instruments in screening for alcohol problem use among adolescents of both sexes ranging from 12 to 19 years of age. We also compared the utility of the abbreviated version to the full-length version, and tested the associations of sex, age, and concurrent depression or other mental disorders on test performance. Finally, cut-off scores are suggested when appropriate.

\section{Methods}

\subsection{Subjects}

The study population $(N=621)$ consisted of three subsamples: psychiatric adolescent outpatients treated for depression in adolescent outpatient clinics between 1998 and 2001 (Depression patients; $N=218$ ) participating the Adolescent Depression Study (ADS), and their age- and sex-matched school-attending adolescent controls (School-attending adolescents 1; $N=200$ ) drawn in 2002 from the enrolment registers of four schools in the same geographical area (Karlsson et al., 2006). The third sample consisted of school-attending adolescent controls (School-attending adolescents 2; $N=203$ ) collected for an adolescent inpatient study between years 2007 and 2010 (the

Table 1

Demographic and clinical characteristics and Cronbach's $\alpha$-values of AUDIT and AUDIT-C for the whole and subsamples.

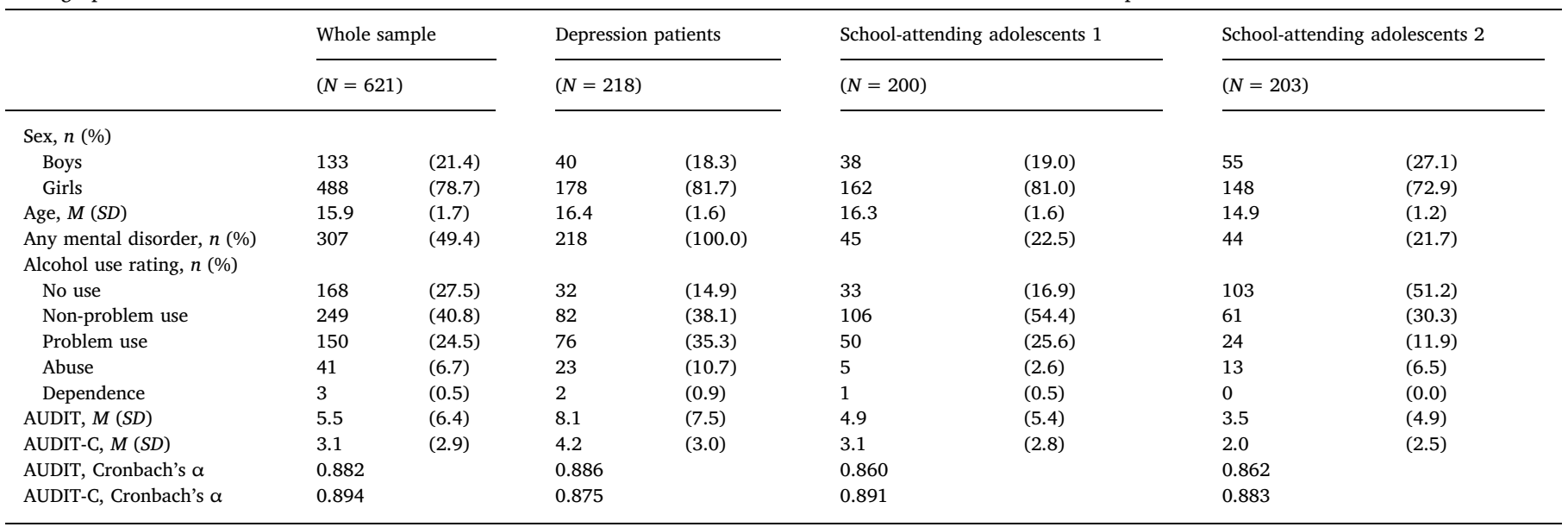


Table 2

The AUDIT and AUDIT-C mean scores $(S D)$ by alcohol use rating in different subgroups.

\begin{tabular}{|c|c|c|c|c|c|c|c|}
\hline \multicolumn{8}{|l|}{ AUDIT, M (SD) } \\
\hline & $\begin{array}{l}\text { No use } \\
(n=168)\end{array}$ & $\begin{array}{l}\text { Non-problem use } \\
(n=249)\end{array}$ & $\begin{array}{l}\text { Problem use } \\
(n=150)\end{array}$ & $\begin{array}{l}\text { Abuse } \\
(n=41)\end{array}$ & $\begin{array}{l}\text { Dependence } \\
(n=3)\end{array}$ & Kruskal-Wallis & $p$ \\
\hline Whole sample & $0.3(0.7)$ & $4.0(3.5)$ & $10.7(5.7)$ & $16.3(6.3)$ & $27.0(4.4)$ & 403.77 & $<0.001$ \\
\hline Depression patients & $0.3(1.0)$ & $4.7(4.2)$ & $11.6(6.5)$ & $16.7(7.1)$ & $28.5(5.0)$ & 118.12 & $<0.001$ \\
\hline School-attending adolescents 1 & $0.3(0.9)$ & $3.6(3.3)$ & $9.4(4.7)$ & $19.2(7.2)$ & 24.0 (.) n.a. & 101.42 & $<0.001$ \\
\hline School-attending adolescents 2 & $0.2(0.6)$ & $3.7(2.4)$ & $10.5(4.3)$ & $14.4(3.7)$ & . & 143.74 & $<0.001$ \\
\hline \multicolumn{8}{|l|}{ Sex } \\
\hline Boys & $0.2(0.7)$ & $4.6(3.6)$ & $9.3(4.6)$ & $17.5(7.3)$ & . & 87.48 & $<0.001$ \\
\hline Girls & $0.3(0.8)$ & $3.8(3.4)$ & $11.0(5.9)$ & $15.8(5.8)$ & $27.0(4.4)$ & 315.11 & $<0.001$ \\
\hline \multicolumn{8}{|l|}{ Age groups } \\
\hline $12-15$ & $0.3(0.8)$ & $3.3(3.8)$ & $9.8(4.7)$ & $13.6(3.6)$ & $25.0()$. & 143.62 & $<0.001$ \\
\hline $16-20$ & $0.2(0.7)$ & $4.4(3.1)$ & $11.0(6.0)$ & $17.8(7.0)$ & $28.0(5.7)$ & 213.40 & $<0.001$ \\
\hline \multicolumn{8}{|l|}{ Any mental disorder } \\
\hline Yes & $0.4(1.0)$ & $4.3(3.9)$ & $11.3(6.1)$ & $16.3(6.3)$ & $27.0(4.4)$ & 274.24 & $<0.001$ \\
\hline No & $0.2(0.6)$ & $3.7(3.1)$ & $9.2(4.2)$ & . & . & 176.65 & $<0.001$ \\
\hline Median scores (min-max) & $0(0-4)$ & $4(0-17)$ & $10(1-18)$ & $16(4-29)$ & $25(24-32)$ & . & . \\
\hline \multicolumn{8}{|l|}{ AUDIT-C, $M(S D)$} \\
\hline & No use & Non-problem use & Problem use & Abuse & Dependence & Kruskal-Wallis & $p$ \\
\hline Whole sample & $0.2(0.6)$ & $2.8(2.1)$ & $5.7(2.0)$ & $7.1(2.1)$ & $9.7(0.6)$ & 379.43 & $<0.001$ \\
\hline Depression patients & $0.3(1.0)$ & $3.1(2.2)$ & $5.7(2.2)$ & $7.6(1.7)$ & $9.5(0.7)$ & 111.80 & $<0.001$ \\
\hline School-attending adolescents 1 & $0.2(0.7)$ & $2.6(2.2)$ & $5.6(1.9)$ & $9.0(2.0)$ & 10.0 (.)n.a. & 99.07 & $<0.001$ \\
\hline School-attending adolescents 2 & $0.2(0.5)$ & $2.9(1.8)$ & $5.8(1.5)$ & $5.6(1.8)$ & . & 137.61 & $<0.001$ \\
\hline \multicolumn{8}{|l|}{ Sex } \\
\hline Boys & $0.1(0.4)$ & $3.5(2.4)$ & $6.1(2.1)$ & $7.9(2.5)$ & . & 87.20 & $<0.001$ \\
\hline Girls & $0.2(0.7)$ & $2.7(2.0)$ & $5.6(2.0)$ & $6.9(1.9)$ & $9.7(0.6)$ & 290.74 & $<0.001$ \\
\hline \multicolumn{8}{|l|}{ Age groups } \\
\hline $12-15$ & $0.2(0.6)$ & $2.2(2.2)$ & $5.0(1.7)$ & $6.1(1.8)$ & $9.0()$. & 134.65 & $<0.001$ \\
\hline $16-20$ & $0.2(0.5)$ & $3.2(1.9)$ & $6.0(2.0)$ & $7.8(2.0)$ & $10.0(0.0)$ & 198.92 & $<0.001$ \\
\hline \multicolumn{8}{|l|}{ Any mental disorder } \\
\hline Yes & $0.3(0.9)$ & $2.8(2.19)$ & $5.7(2.1)$ & $7.1(2.1)$ & $9.7(0.6)$ & 166.84 & $<0.001$ \\
\hline No & $0.2(0.5)$ & $2.8(2.1)$ & $5.8(1.8)$ & . & . & 177.47 & $<0.001$ \\
\hline Median scores (min-max) & $0(0-4)$ & $3(0-8)$ & $6(1-12)$ & $8(3-12)$ & $10(9-10)$ & . & . \\
\hline
\end{tabular}

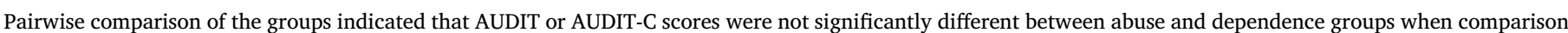

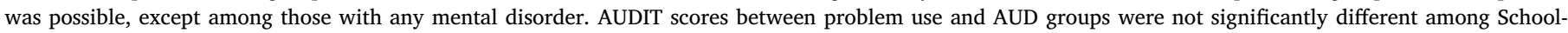

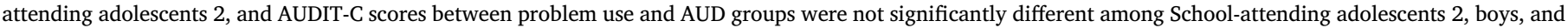
younger adolescents aged 12-15.

Table 3

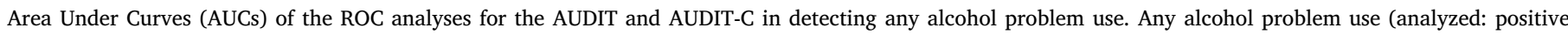
$n=188$, negative $n=407$ ).

\begin{tabular}{|c|c|c|c|c|c|c|c|c|c|c|}
\hline & \multicolumn{3}{|l|}{ AUDIT } & \multicolumn{3}{|c|}{ AUDIT-C } & \multicolumn{4}{|c|}{ Pairwise comparisons of ROC curves } \\
\hline & AUC & SE & $(95 \% \mathrm{CI})$ & AUC & SE & $(95 \% \mathrm{CI})$ & Difference between areas & SE & $\mathrm{Z}$ & $\mathrm{p}$ \\
\hline Whole sample & 0.934 & 0.010 & $(0.911-0.953)$ & 0.912 & 0.011 & $(0.886-0.933)$ & 0.022 & 0.007 & 3.30 & $0.001^{k *}$ \\
\hline Depression patients & 0.896 & 0.021 & $(0.845-0.935)$ & 0.877 & 0.024 & $(0.823-0.919)$ & 0.019 & 0.015 & 1.29 & 0.197 \\
\hline School-attending 1 & 0.897 & 0.022 & $(0.845-0.936)$ & 0.889 & 0.023 & $(0.836-0.929)$ & 0.008 & 0.012 & 0.70 & 0.486 \\
\hline School-attending 2 & 0.992 & 0.004 & $(0.968-0.999)$ & 0.956 & 0.013 & $(0.918-0.980)$ & 0.036 & 0.011 & 3.19 & $0.001^{k * *}$ \\
\hline Boys & 0.918 & 0.023 & $(0.855-0.959)$ & 0.915 & 0.024 & $(0.852-0.957)$ & 0.003 & 0.013 & 0.19 & 0.847 \\
\hline Girls & 0.938 & 0.010 & $(0.913-0.958)$ & 0.912 & 0.013 & $(0.883-0.936)$ & 0.027 & 0.008 & 3.45 & $<0.001^{* \ldots * k}$ \\
\hline Ages $12-15$ & 0.954 & 0.012 & $(0.921-0.976)$ & 0.931 & 0.015 & $(0.893-0.959)$ & 0.023 & 0.010 & 2.33 & $0.020^{*}$ \\
\hline Ages $16-19$ & 0.912 & 0.015 & $(0.877-0.941)$ & 0.890 & 0.017 & $(0.851-0.922)$ & 0.022 & 0.010 & 2.35 & $0.019^{\prime \prime}$ \\
\hline Any mental disorder & 0.921 & 0.015 & $(0.884-0.949)$ & 0.894 & 0.018 & $(0.853-0.927)$ & 0.027 & 0.012 & 2.28 & $0.023^{*}$ \\
\hline No mental disorder & 0.924 & 0.017 & $(0.889-0.951)$ & 0.920 & 0.017 & $(0.884-0.948)$ & 0.004 & 0.009 & 0.45 & 0.651 \\
\hline
\end{tabular}

$$
\begin{aligned}
& * p<.05 . \\
& * * p<.01 . \\
& * * * p<.001 .
\end{aligned}
$$

Kellokoski Adolescent Inpatient Follow-Up Study, KAIFUS, 2006-2010). The sample consisted of 133 males (21\%) and 488 females (78\%) (Table 1). The mean age of the participants was 15.9 years (range 12-19 years), and there were 271 (44\%) adolescents aged 12-15 and $350(56 \%)$ aged 16-19. All Depression patients had a current depressive disorder and a comorbid psychiatric disorder was diagnosed in $78.4 \%$ ( $n=171$; any anxiety disorder $57.3 \%$, any substance use disorder
$16.5 \%$, disruptive disorder $10.1 \%$, eating disorder 10.1\%) (Karlsson et al., 2006). There was a current mental disorder in 45 (22.5\%) of the Schoolattending adolescents group 1 (any mood disorder $11.0 \%$, any anxiety disorder $11.5 \%$, any substance use disorder $4.0 \%$, disruptive disorder $4.5 \%$, eating disorders $4.0 \%)$ and in $44(21.7 \%)$ of the School-attending adolescents group 2 (any mood disorder 1.5\%, any anxiety disorder $6.4 \%$, any substance use disorder 7.9\%, conduct disorder 1.5\%, ADHD 2.0\%, 


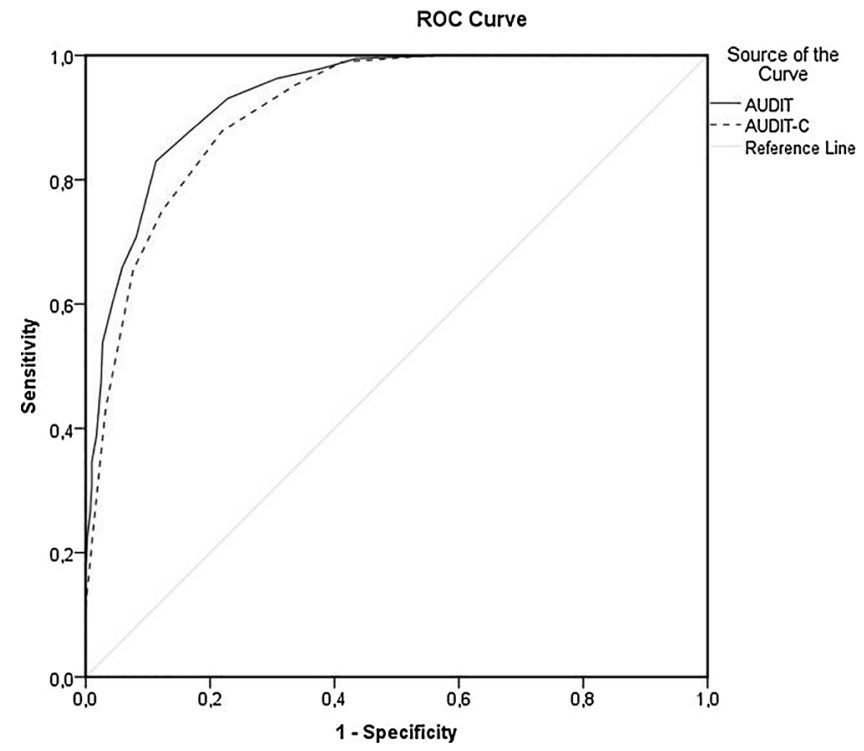

Fig. 1. Receiver operating characteristic (ROC) curves of the AUDIT and AUDIT-C sum scores in detecting alcohol problem use in the whole sample.

eating disorders $2.0 \%$ ).

Study approval was granted for both outpatient and inpatient studies by the Ethics Committee of the Hospital District of Helsinki and Uusimaa (Helsinki University Hospital).

\subsection{Diagnostic interview}

Psychiatric diagnoses according to DSM-IV, including AUDs, i.e., alcohol abuse and dependence, were assigned using the Finnish translation of the Schedule for Affective Disorders and Schizophrenia for School-Age Children - Present and Life-Time (K-SADS-PL) interview (Kaufman et al., 1997). K-SADS-PL is a semi-structured interview widely used in adolescent psychiatric research with good to excellent test-retest reliability and high concurrent validity and inter-rater agreement between the original and translated versions (Kaufman et al., 1997; Ambrosini, 2000). Interviews were conducted by mental health professionals trained in the method and psychiatrists specialized in treating adolescents assigned the psychiatric diagnoses based on the K-SADS-PL.

\subsection{Alcohol use rating}

Adolescents' alcohol use during the previous 12 months was rated into five mutually exclusive categories based on the following: the KSADS-PL interview open (entry) questions about alcohol use habits, the AUD screening and the symptom criteria questions. Rating similar to that used by Knight et al. (2003) was applied: No use was rated when there was no reported drinking during the past year. Non-problem use was rated when there was any reported drinking during the past year, but no reported alcohol-related problems. Problem use was defined as one or more reported alcohol-related problems (i.e., at least one AUD symptom criterion was met) that did not reach the diagnostic threshold for a specific AUD. The Problem use rating was also used when there was any reported engagement in heavy binge drinking or blackouts due to alcohol intoxication, allowing some freedom for clinical decision making with regard to age and duration of the behavior. The Alcohol abuse and the Alcohol dependence ratings were applied according to the DSM-IV criteria (American Psychiatric Association, 1994). Alcohol use ratings were further used in the analyses as a dichotomy: the any problem use rating included problem use, abuse, or dependence. Proportions of the problem use, abuse, and dependence groups were 150 (24.5\%), 41 $(6.7 \%)$ and $3(0.5 \%)$ (Table 1), respectively. All alcohol-dependent participants were females.

\subsection{The AUDIT and AUDIT-C}

Subjects filled in the Finnish translation of the 10-item AUDIT form (Babor et al., 2001). Questions were scored from 0 to 4, which allowed for a maximum sum score of 40 . The AUDIT-C contained the first three questions of the original AUDIT, which allowed a maximum sum score of 12 (Bush et al., 1998).

If a participant scored "0" on the first question and (often) left other questions unanswered indicating not using alcohol, then he/she was given a sum score of zero when calculating the sum scores for both the AUDIT and AUDIT-C questionnaires. A single missing item was imputed by using the calculated mean of the other items when calculating the AUDIT sum scores. If more than one answer was missing, the questionnaire was excluded.

\subsection{Statistical analyses}

Results are presented as frequencies, percentages, means $(M)$ with standard deviations $(S D)$ and medians with ranges. The AUDIT and AUDIT-C scale properties were analyzed using Cronbach's $\alpha$ for calculating internal consistency, Kolmogorov-Smirnov tests to assess normality of the sum scores, and correlation between the AUDIT and AUDIT-C sum scores were analyzed using Spearman's rho. Differences in the AUDIT and AUDIT-C scores between different groups were analyzed using the Kruskal-Wallis test and for the pairwise comparison of subgroups, which were performed according to Conover (1999).

Receiver operating characteristic (ROC) curves and associated area under the curve (AUC) values with binomial exact 95\% confidence intervals (CI) were computed to asses screening performance of the AUDIT and AUDIT-C for any alcohol problem use and for different subgroups (males and females, younger and older adolescent age groups, 12-15 and 16-19 years; adolescents with and without any mental disorder, majority suffering from depression (DeLong et al., 1988; Faraggi and Reiser, 2002; Irwin, 2009). AUC value of 1.0 indicates a perfect test and 0.5 a worthless test, values from 0.7 to 0.79 indicate fair accuracy, from 0.8 to 0.89 good accuracy, and over 0.9 indicates excellent accuracy of the test. The method introduced by Delong et al. (1988) was used to calculate the standard error (SE) of the AUC and the differences between the pairs of the AUCs produced with the AUDIT and AUDIT-C.

Screening parameters including sensitivity, specificity, positive predictive values (PPV), negative predictive values (NPV), positive likelihood ratios $(\mathrm{LR}+)$ negative likelihood ratios $(\mathrm{LR}-)$ and also diagnostic odds ratios (dOR) were calculated for the different AUDIT and AUDIT-C cut-off scores. The dOR expresses the overall discrimination between the chosen cut-offs. The possible values of dOR ranged from zero to infinity. The value of one signifies that the test has no discriminatory capacity between healthy and sick groups. A value greater than one indicates discriminatory level, which will be greater the higher the value is. We also included those adolescents in the analyses who had reported no alcohol use as a normal state in this age-group although this especially affects the specificity.

Youden's J statistic, traditionally used to select the best cut-off, maximizes the sum of sensitivity and specificity and assumes that they have equal weight in decision making (Youden, 1950). However, the prevalence of the condition in the screened population and the ratio of the costs of additional diagnostics and interventions resulting from false-positive screening results should be compared with the benefits derived from interventions with true-positive results (Cantor et al., 1999; Smits, 2010). We calculated both weighted Youden indices ( $J w)$ weighting sensitivity and specificity in 60:40 and 75:25 ratios (Li et al., 2013). The costs of a decision resulting in a false positive was assigned an estimated cost of 1 , whereas a false negative was assigned an estimated cost of 4 , and no specific value was placed on true positive and true negative results (valued 0) to provide optimal cut-off. Cohen's 
Table 4

Performance of the different AUDIT cut-off scores in detecting any alcohol problem use in different subgroups.

\begin{tabular}{|c|c|c|c|c|c|c|c|c|c|c|c|c|}
\hline \multirow[b]{2}{*}{ AUDIT cut-off } & \multicolumn{6}{|c|}{ Whole sample } & \multicolumn{6}{|c|}{ Any mental disorder } \\
\hline & $\geq 3$ & $\geq 4$ & $\geq 5$ & $\geq 6$ & $\geq 7$ & $\geq 8$ & $\geq 3$ & $\geq 4$ & $\geq 5$ & $\geq 6$ & $\geq 7$ & $\geq 8$ \\
\hline Sensitivity & 0.979 & 0.963 & 0.931 & 0.878 & 0.830 & 0.707 & 0.986 & 0.965 & 0.944 & 0.888 & 0.853 & 0.748 \\
\hline Specificity & 0.622 & 0.693 & 0.772 & 0.833 & 0.887 & 0.919 & 0.545 & 0.628 & 0.724 & 0.793 & 0.855 & 0.890 \\
\hline PPV & 0.544 & 0.592 & 0.653 & 0.708 & 0.772 & 0.801 & 0.681 & 0.719 & 0.771 & 0.809 & 0.853 & 0.870 \\
\hline NPV & 0.984 & 0.976 & 0.960 & 0.936 & 0.919 & 0.872 & 0.975 & 0.948 & 0.929 & 0.878 & 0.855 & 0.782 \\
\hline $\mathrm{LR}+$ & 2.59 & 3.13 & 4.07 & 5.25 & 7.34 & 8.73 & 2.17 & 2.59 & 3.42 & 4.29 & 5.89 & 6.68 \\
\hline LR - & 0.034 & 0.054 & 0.090 & 0.150 & 0.190 & 0.320 & 0.026 & 0.056 & 0.077 & 0.140 & 0.170 & 0.280 \\
\hline DOR & 76.18 & 57.96 & 45.22 & 35.00 & 38.63 & 27.28 & 83.46 & 46.25 & 44.42 & 30.64 & 34.65 & 24.21 \\
\hline Youden's $J$ & 0.600 & 0.656 & 0.702 & 0.711 & 0.717 & 0.626 & 0.531 & 0.593 & 0.668 & 0.681 & 0.708 & 0.638 \\
\hline Weighted $J^{1}(\mathrm{w}=0.6)$ & 0.672 & 0.710 & 0.734 & 0.720 & 0.705 & 0.584 & 0.625 & 0.661 & 0.714 & 0.698 & 0.706 & 0.608 \\
\hline Weighted $J^{1}(\mathrm{w}=0.75)$ & 0.779 & 0.791 & 0.782 & 0.733 & 0.688 & 0.521 & 0.755 & 0.762 & 0.780 & 0.727 & 0.706 & 0.566 \\
\hline \multirow[t]{2}{*}{ Cost } & 0.286 & 0.257 & 0.244 & 0.296 & 0.292 & 0.425 & 0.257 & 0.257 & 0.250 & 0.326 & 0.365 & 0.556 \\
\hline & \multicolumn{6}{|c|}{ Ages $12-15$} & \multicolumn{6}{|c|}{ Ages 16-19 } \\
\hline AUDIT cut-off & $\geq 3$ & $\geq 4$ & $\geq 5$ & $\geq 6$ & $\geq 7$ & $\geq 8$ & $\geq 3$ & $\geq 4$ & $\geq 5$ & $\geq 6$ & $\geq 7$ & $\geq 8$ \\
\hline Sensitivity & 0.963 & 0.944 & 0.926 & 0.870 & 0.870 & 0.741 & 0.985 & 0.970 & 0.933 & 0.881 & 0.813 & 0.694 \\
\hline Specificity & 0.780 & 0.818 & 0.857 & 0.890 & 0.919 & 0.943 & 0.455 & 0.561 & 0.682 & 0.773 & 0.854 & 0.894 \\
\hline PPV & 0.536 & 0.578 & 0.630 & 0.676 & 0.739 & 0.775 & 0.549 & 0.598 & 0.664 & 0.723 & 0.789 & 0.815 \\
\hline NPV & 0.988 & 0.982 & 0.978 & 0.963 & 0.964 & 0.932 & 0.978 & 0.965 & 0.938 & 0.906 & 0.872 & 0.813 \\
\hline $\mathrm{LR}+$ & 4.38 & 5.19 & 6.45 & 7.91 & 10.70 & 12.90 & 1.81 & 2.21 & 2.93 & 3.87 & 5.55 & 6.54 \\
\hline LR - & 0.047 & 0.068 & 0.086 & 0.150 & 0.280 & 0.370 & 0.033 & 0.053 & 0.099 & 0.15 & 0.22 & 0.34 \\
\hline DOR & 93.19 & 76.32 & 75.00 & 54.73 & 39.21 & 34.86 & 54.85 & 41.70 & 29.60 & 25.80 & 25.23 & 19.24 \\
\hline Youden's $J$ & 0.743 & 0.763 & 0.782 & 0.760 & 0.789 & 0.683 & 0.440 & 0.531 & 0.615 & 0.653 & 0.667 & 0.588 \\
\hline Weighted $J^{1}(\mathrm{w}=0.6)$ & 0.780 & 0.788 & 0.796 & 0.756 & 0.779 & 0.643 & 0.546 & 0.613 & 0.665 & 0.675 & 0.659 & 0.548 \\
\hline Weighted $J^{1}(\mathrm{w}=0.75)$ & 0.834 & 0.826 & 0.817 & 0.750 & 0.765 & 0.582 & 0.705 & 0.735 & 0.740 & 0.707 & 0.647 & 0.488 \\
\hline \multirow[t]{2}{*}{ Cost } & 0.205 & 0.190 & 0.175 & 0.194 & 0.171 & 0.259 & 0.349 & 0.310 & 0.298 & 0.328 & 0.389 & 0.557 \\
\hline & \multicolumn{6}{|l|}{ Girls } & \multicolumn{6}{|l|}{ Boys } \\
\hline AUDIT cut-off & $\geq 3$ & $\geq 4$ & $\geq 5$ & $\geq 6$ & $\geq 7$ & $\geq 8$ & $\geq 3$ & $\geq 4$ & $\geq 5$ & $\geq 6$ & $\geq 7$ & $\geq 8$ \\
\hline Sensitivity & 0.987 & 0.966 & 0.946 & 0.899 & 0.846 & 0.732 & 0.949 & 0.949 & 0.872 & 0.795 & 0.769 & 0.615 \\
\hline Specificity & 0.609 & 0.684 & 0.772 & 0.834 & 0.888 & 0.919 & 0.667 & 0.724 & 0.770 & 0.828 & 0.885 & 0.913 \\
\hline PPV & 0.541 & 0.588 & 0.659 & 0.716 & 0.777 & 0.808 & 0.567 & 0.613 & 0.635 & 0.680 & 0.755 & 0.779 \\
\hline NPV & 0.990 & 0.977 & 0.968 & 0.947 & 0.925 & 0.880 & 0.966 & 0.969 & 0.929 & 0.898 & 0.893 & 0.893 \\
\hline$+\mathrm{LR}$ & 2.53 & 3.06 & 4.15 & 5.43 & 7.52 & 9.00 & 2,85 & 3.44 & 3.79 & 4.61 & 6.69 & 7.65 \\
\hline$-\mathrm{LR}$ & 0.022 & 0.049 & 0.07 & 0.12 & 0.17 & 0.29 & 0.077 & 0.071 & 0.17 & 0.25 & 0.26 & 0.42 \\
\hline DOR & 115.00 & 62.45 & 59.29 & 44.24 & 44.24 & 31.03 & 37.01 & 48.45 & 22.29 & 18.44 & 25.73 & 18.21 \\
\hline Youden's $J$ & 0.596 & 0.650 & 0.718 & 0.733 & 0.733 & 0.651 & 0.615 & 0.673 & 0.642 & 0.623 & 0.654 & 0.528 \\
\hline Weighted $J^{1}(\mathrm{w}=0.6)$ & 0.672 & 0.706 & 0.753 & 0.746 & 0.725 & 0.614 & 0.672 & 0.718 & 0.662 & 0.616 & 0.631 & 0.474 \\
\hline Weighted $J^{1}(\mathrm{w}=0.75)$ & 0.781 & 0.791 & 0.805 & 0.766 & 0.713 & 0.558 & 0.757 & 0.790 & 0.693 & 0.607 & 0.596 & 0.383 \\
\hline Cost & 0.284 & 0.258 & 0.224 & 0.241 & 0.273 & 0.397 & 0.294 & 0.254 & 0.317 & 0.373 & 0.365 & 0.532 \\
\hline
\end{tabular}

The bolded values define the recommended cut-offs that were chosen for AUDIT and AUDIT-C.

kappa was calculated to measure the level of agreement on screening status between the AUDIT and AUDIT-C with suggested cut-off scores.

All models and scores were estimated using all available data, assuming missing data were due to randomness. All tests were two-tailed, and the level of significance was set at $\mathrm{p}<0.05$. The SPSS 22 and MedCalc version 16.5 software were used for the analyses.

\section{Results}

\subsection{Basic properties of the AUDIT and AUDIT-C}

Cronbach's $\alpha$ for AUDIT was good for the whole sample and for all subsamples varying from 0.860 to 0.886 . The corresponding Cronbach's $\alpha$ values for AUDIT-C varied between 0.875 and 0.894 , also showing a good internal consistency.

The mean sum score in the whole sample for the AUDIT was $5.5 \pm 6.4$, median: $4(0-38)$ and for the AUDIT-C $3.1 \pm 2.9$, median: $3(0-12)$. There was a floor effect in the sum-score distributions (skewness) of 1.54 for the AUDIT and 0.54 for AUDIT-C, whereas the Kolmogorov-Smirnov tests suggested rejection of normality. Correlation between the AUDIT and AUDIT-C sum scores was high in the whole sample (with Spearman's rho: 0.962) and in all the subsamples
(0.928-0.982).

\subsection{Differences of AUDIT and AUDIT-C in detecting alcohol use level}

Mean values of the AUDIT and AUDIT-C in the different alcohol use rating groups are shown in Table 2. The mean AUDIT sum scores increased for all the subgroups according to alcohol use. Kruskal-Wallis tests comparing the differences in the AUDIT and AUDIT-C sum scores between the alcohol use rating groups showed significant differences in the tested subgroups.

Pairwise comparison of the groups indicated that the AUDIT and AUDIT-C scores were not significantly different between abuse and dependence groups when a comparison was possible (except among those with any mental disorder).

\subsection{Comparison of the screening performance of the AUDIT and AUDIT-C}

ROCAUC analyses indicated that both AUDIT and AUDIT-C performed well in all the analyzed subgroups in detecting any alcohol problem use (Table 3, Fig. 1). Comparisons of the ROC curve pairs for AUDIT and AUDIT-C indicated somewhat better performance by the AUDIT in the whole sample, in the subsample "School-attending 
Table 5

Performance of the different AUDIT-C cut-off scores in detecting any alcohol problem use in different subgroups.

\begin{tabular}{|c|c|c|c|c|c|c|c|c|c|c|c|c|}
\hline \multirow[b]{2}{*}{ AUDIT-C cut-off } & \multicolumn{6}{|c|}{ Whole sample } & \multicolumn{6}{|c|}{ Any mental disorder } \\
\hline & $\geq 2$ & $\geq 3$ & $\geq 4$ & $\geq 5$ & $\geq 6$ & $\geq 7$ & $\geq 2$ & $\geq 3$ & $\geq 4$ & $\geq 5$ & $\geq 6$ & $\geq 7$ \\
\hline Sensitivity & 0.989 & 0.952 & 0.878 & 0.750 & 0.654 & 0.431 & 0.993 & 0.951 & 0.867 & 0.741 & 0.671 & 0.448 \\
\hline Specificity & 0.587 & 0.664 & 0.781 & 0.877 & 0.924 & 0.968 & 0.503 & 0.593 & 0.731 & 0.862 & 0.917 & 0.959 \\
\hline PPV & 0.528 & 0.568 & 0.651 & 0.740 & 0.805 & 0.863 & 0.664 & 0.697 & 0.761 & 0.841 & 0.889 & 0.914 \\
\hline NPV & 0.991 & 0.967 & 0.932 & 0.883 & 0.852 & 0.785 & 0.986 & 0.925 & 0.848 & 0.772 & 0.739 & 0.638 \\
\hline $\mathrm{LR}+$ & 2.4 & 2.83 & 4.01 & 6.10 & 8.59 & 13.49 & 2.00 & 2.34 & 3.22 & 5.37 & 8.11 & 10.82 \\
\hline LR - & 0.018 & 0.072 & 0.16 & 0.29 & 0.37 & 0.59 & 0.014 & 0.083 & 0.18 & 0.30 & 0.36 & 0.58 \\
\hline DOR & 133.33 & 39.31 & 25.06 & 21.03 & 23.22 & 22.86 & 142.86 & 28.19 & 17.89 & 17.90 & 22.53 & 18.66 \\
\hline Youden's $J$ & 0.577 & 0.616 & 0.659 & 0.627 & 0.578 & 0.399 & 0.496 & 0.544 & 0.598 & 0.603 & 0.589 & 0.406 \\
\hline Weighted $J^{1}(\mathrm{w}=0.6)$ & 0.657 & 0.674 & 0.678 & 0.602 & 0.524 & 0.292 & 0.594 & 0.616 & 0.625 & 0.579 & 0.539 & 0.304 \\
\hline Weighted $J^{1}(\mathrm{w}=0.75)$ & 0.777 & 0.760 & 0.707 & 0.564 & 0.443 & 0.130 & 0.741 & 0.723 & 0.666 & 0.543 & 0.466 & 0.151 \\
\hline \multirow[t]{2}{*}{ Cost } & 0.296 & 0.291 & 0.304 & 0.400 & 0.489 & 0.741 & 0.264 & 0.302 & 0.399 & 0.583 & 0.694 & 1.118 \\
\hline & \multicolumn{6}{|c|}{ Ages 12-15 } & \multicolumn{6}{|c|}{ Ages 16-19 } \\
\hline AUDIT-C cut-off & $\geq 2$ & $\geq 3$ & $\geq 4$ & $\geq 5$ & $\geq 6$ & $\geq 7$ & $\geq 2$ & $\geq 3$ & $\geq 4$ & $\geq 5$ & $\geq 6$ & $\geq 7$ \\
\hline Sensitivity & 0.982 & 0.944 & 0.833 & 0.630 & 0.482 & 0.296 & 0.993 & 0.955 & 0.896 & 0.799 & 0.724 & 0.485 \\
\hline Specificity & 0.761 & 0.794 & 0.861 & 0.938 & 0.962 & 0.981 & 0.404 & 0.525 & 0.697 & 0.813 & 0.884 & 0.955 \\
\hline PPV & 0.515 & 0.543 & 0.608 & 0.723 & 0.765 & 0.800 & 0.530 & 0.577 & 0.667 & 0.743 & 0.808 & 0.878 \\
\hline NPV & 0.994 & 0.982 & 0.952 & 0.907 & 0.878 & 0.844 & 0.988 & 0.945 & 0.908 & 0.856 & 0.825 & 0.733 \\
\hline $\mathrm{LR}+$ & 4.10 & 4.59 & 6.01 & 10.12 & 12.58 & 15.48 & 1.67 & 2.01 & 2.96 & 4.27 & 6.23 & 10.67 \\
\hline LR - & 0.024 & 0.070 & 0.19 & 0.39 & 0.54 & 0.72 & 0.018 & 0.085 & 0.15 & 0.25 & 0.31 & 0.54 \\
\hline DOR & 170.83 & 65.57 & 31.63 & 25.95 & 23.30 & 21.50 & 92.78 & 23.65 & 19.73 & 17.08 & 20.10 & 19.76 \\
\hline Youden's $J$ & 0.742 & 0,739 & 0,695 & 0.567 & 0.443 & 0.277 & 0.397 & 0.480 & 0.593 & 0.612 & 0.608 & 0.440 \\
\hline Weighted $J^{1}(\mathrm{w}=0.6)$ & 0.786 & 0.769 & 0.689 & 0.506 & 0.347 & 0.140 & 0.514 & 0.566 & 0.632 & 0.609 & 0.576 & 0.346 \\
\hline Weighted $J^{1}(\mathrm{w}=0.75)$ & 0.853 & 0.814 & 0.681 & 0.413 & 0.203 & -0.065 & 0.691 & 0.695 & 0.692 & 0.604 & 0.528 & 0.205 \\
\hline \multirow[t]{2}{*}{ Cost } & 0.205 & 0.209 & 0.247 & 0.354 & 0.456 & 0.593 & 0.367 & 0.355 & 0.349 & 0.437 & 0.515 & 0.858 \\
\hline & \multicolumn{6}{|l|}{ Girls } & \multicolumn{6}{|l|}{ Boys } \\
\hline AUDIT-C cut-off & $\geq 2$ & $\geq 3$ & $\geq 4$ & $\geq 5$ & $\geq 6$ & $\geq 7$ & $\geq 2$ & $\geq 3$ & $\geq 4$ & $\geq 5$ & $\geq 6$ & $\geq 7$ \\
\hline Sensitivity & 0.987 & 0.960 & 0.866 & 0.745 & 0.631 & 0.403 & 1.00 & 0.923 & 0.923 & 0.769 & 0.744 & 0.539 \\
\hline Specificity & 0.569 & 0.653 & 0.784 & 0.891 & 0.934 & 0.972 & 0.655 & 0.701 & 0.770 & 0.828 & 0.885 & 0.954 \\
\hline PPV & 0.516 & 0.563 & 0.652 & 0.760 & 0.817 & 0.870 & 0.565 & 0.581 & 0.643 & 0.667 & 0.744 & 0.840 \\
\hline NPV & 0.989 & 0.972 & 0.926 & 0.882 & 0.845 & 0.777 & 1.00 & 0.953 & 0.957 & 0.889 & 0.885 & 0.822 \\
\hline $\mathrm{LR}+$ & 2.29 & 2.77 & 4.02 & 6.81 & 9.61 & 14.32 & 2.90 & 3.09 & 4.02 & 4.46 & 6.47 & 11.71 \\
\hline LR - & 0.024 & 0.062 & 0.17 & 0.29 & 0.40 & 0.61 & 0.00 & 0.11 & 0.10 & 0.28 & 0.29 & 0.48 \\
\hline DOR & 95.42 & 44.68 & 23.65 & 23.48 & 24.03 & 23.48 & N/A & 28.09 & 40.20 & 15.93 & 22.31 & 24.31 \\
\hline Youden's $J$ & 0.555 & 0.613 & 0.650 & 0.636 & 0.565 & 0.375 & 0.655 & 0.624 & 0.693 & 0.597 & 0.629 & 0.493 \\
\hline Weighted $J^{1}(\mathrm{w}=0.6)$ & 0.639 & 0.674 & 0.666 & 0.606 & 0.505 & 0.261 & 0.724 & 0.668 & 0.724 & 0.585 & 0.601 & 0.410 \\
\hline Weighted $J^{1}(\mathrm{w}=0.75)$ & 0.764 & 0.766 & 0.691 & 0.563 & 0.414 & 0.090 & 0.828 & 0.735 & 0.770 & 0.568 & 0.559 & 0.286 \\
\hline Cost & 0.311 & 0.288 & 0.318 & 0.399 & 0.514 & 0.778 & 0.238 & 0.302 & 0.254 & 0.405 & 0.397 & 0.603 \\
\hline
\end{tabular}

adolescents group 2", girls, older and younger adolescent groups, and adolescents with any mental disorder, whereas performance was equal among the rest of the subgroups (Table 3).

\subsection{Cut-offs for detecting problem use of alcohol}

Criterion values (sensitivity, specificity, positive and negative predictive value, positive and negative likelihood ratios) for the different cut-off scores original and weighted Youden's indices and cost of a decision were calculated for detecting any alcohol problem use in the different subgroups.

The analyses suggested an optimal cut-off score of $\geq 5$ for the AUDIT for the whole sample with the dOR of 45.22 (95\% CI: 24.72-83.57; Table 4). Lower cut-off value was suggested for the depression patients but when all adolescents with any mental disorder were included the lower value was no longer supported. Optimal cut-off score for the AUDIT-C for the whole sample was $\geq 3$ (dOR 39.31; 95\% CI: 19.46-78.97; Table 5).

When these cut-off scores according to the age were used, the AUDIT-C quite effectively identified the same adolescent population as the full AUDIT. The AUDIT cut-off $\geq 5$, vs. AUDIT-C cut-off $\geq 3$ yielded agreement in a high proportion (91.9\%, Cohen's kappa 0.837 ) of the adolescents.

\section{Discussion}

The aim of this study was to validate the AUDIT and the AUDIT-C questionnaires as screening instruments for alcohol problem use among adolescents. A good screening instrument has high sensitivity and high specificity, i.e., cut-off scores for screening tests are designed to maximize sensitivity and specificity in order to minimize false-positives and false-negatives (Pilowsky and Wu, 2013). Consequently, the traditional Youden's J statistic assumes that sensitivity and specificity are equally valued. However, the choice of a cut-off is not solely a statistical decision, and as earlier studies have found, the cut-off score should be tailored according to age, sex, and cultural differences in alcohol consumption (Altman, 1991; Reinert and Allen, 2002; von der Pahlen et al., 2008). Altman emphasized that when screening an "ostensibly" healthy population, it is very important to have high sensitivity and negative predictive value, whereas the requirement for a diagnostic test is high sensitivity and positive predictive values, because a positive result may lead to clinical intervention and thus this comes down to the costs of the different decisions made based on the test result (Altman, 1991).

We weighted Youden's indices to increase sensitivity over specificity and also adjust the costs of a decision when a false negative result was rated higher compared to a false positive result (Li et al., 2013). The detection of problematic alcohol use as early as possible was considered 
to be crucial. Using indifference curves to maximize expected utility is another method described to choose optimal cut-off score while more individualized interpretation of the test results could be achieved using Bayes' theorem post-test probability estimates according to Bayes' theorem (Irwin and Irwin, 2011; Foxcroft et al., 2015).

Some previous studies also suggested that lower cut-off scores should be used when screening for alcohol problems among adolescents (Chung et al., 2000; Knight et al., 2003; Reinert and Allen, 2007; Demartini and Carey, 2012). Chung et al. (2000) studied 13-19-yearolds presenting to an emergency department for treatment of an injury, and they suggest a cut-off score of $\geq 4$ to be used, as the AUDIT's sensitivity was highest at a cut-off score of $\leq 4$ and specificity was maximized at a cut-off score of $\geq 4$. Knight et al. (2003) found that for AUDIT, a cut-off point of $\geq 2$ was optimal for identifying alcohol problem use and $\geq 3$ for identifying alcohol abuse or dependence in a group of 14-18-year-old patients arriving for a check-up at a hospital based adolescent clinic. Demartini and Carey (2012) recommended that a score of $\geq 8$ is best for the identification of at-risk drinkers using the full AUDIT among college psychology students aged 18-25 years who were recruited from a university department. They reported AUDIT-C identified at-risk drinking more effectively when cut-off scores of $\geq 5$ for females and $\geq 7$ for males were used.

We found that both AUDIT and AUDIT-C performed well among adolescents; they had good internal consistency and good to excellent accuracy. The choice of which instrument to use should be considered, as the AUDIT showed to be only slightly better than its derivative. Moreover, AUDIT-C is shorter and less time-consuming than AUDIT especially when screening larger samples, thus, our data seems to support using AUDIT-C. The accuracy of both of them as a diagnostic instrument to distinguish different alcohol use disorders was not significantly high, which is why both AUDIT and AUDIT-C work better as screening instruments for early problematic alcohol use.

A strength of this study is the relatively large study population, which included both clinical and school-based samples. Another strength was that the adolescents' psychiatric diagnoses and alcohol use ratings during the previous 12 months were based on semi-structured diagnostic interviews. The main limitation was that girls represented almost $80 \%$ of both clinical and school-based samples, which hindered appropriate analyses according to gender. The relatively small number of adolescents with diagnosed alcohol use disorders precluded determining AUDIT and AUDIT-C cut-offs separately for alcohol abuse and dependence. Of the subgroups of study participants analyzed, adolescents in the subgroup with any mental disorder suffered predominantly from depression. Also, the fact that AUDIT-C was derived from the full AUDIT can be seen as a limitation. Had the participants answered differently for AUDIT-C as a unique platform can only be speculated.

\section{Conclusions}

The AUDIT and AUDIT-C are valid instruments for screening alcohol problem use in adolescents. Our data suggest AUDIT cut-off score of $>5$ for screening alcohol problem use both in adolescents with psychiatric disorders and in the general population. Our data suggest a cutoff score of $\geq 3$ when using the AUDIT-C.

\section{Role of funding source}

Joni Liskola received a grant of $2500 €$ from the Finnish Foundation for Psychiatric Research in 2015, which partly relates to the research reported in this article. The Finnish Foundation for Psychiatric Research had no role in either the gathering or the interpretation of these data presented in this article.

\section{Contributors}

MM, HH, NL and JL were responsible of the study concept and design. MM, NL, LK, and SN contributed to the data acquisition. MM, $\mathrm{HH}, \mathrm{OK}$, and JL performed the statistical analyses. JL provided the first version of the manuscript. MM, HH, NL, OK, LK and SN provided critical revision of the manuscript. All authors critically reviewed the content and approved the final version of this manuscript.

\section{Conflicts of interest statement}

The authors declare that they have not had any financial support or other relationships that may have caused any conflict of interest.

\section{References}

Aalto, M., Alho, H., Halme, J.T., Seppa, K., 2009. AUDIT and its abbreviated versions in detecting heavy and binge drinking in a general population survey. Drug Alcohol Depend. 103, 25-29.

American Academy of Pediatrics, Committee of Substance Abuse, 2010. Policy statement: alcohol use by youth and adolescents: a pediatric concern. Pediatrics 108, 185.

American Psychiatric Association, 1994. Diagnostic and Statistical Manual of Mental Disorders. American Psychiatric Association, Washington, DC.

Adewuya, A.O., 2005. Validation of the Alcohol Use Disorders Identification Test (ADUIT) as a screening tool for alcohol-related problems among Nigerian university students. Alcohol Alcohol. 40, 575-577.

Aertgeerts, B., Buntinx, F., Bande-Knops, J., Vandermeulen, C., Roelants, M., Ansoms, S., Fevery, J., 2000. The value of CAGE, CUGE, and AUDIT in screening for alcohol abuse and dependence among college freshmen. Alcohol. Clin. Exp. Res. 24, 53-57.

Altman, D.G., 1991. Practical Statistics for Medical Research. Chapman and Hall/CRC, Boca Raton, FL, pp. 414-419.

Ambrosini, P.J., 2000. Historical development and present status of the schedule for af fective disorders and schizophrenia for school-age children (K-SADS). J. Am. Acad. Child Adolesc. Psychiatry 39, 49-58.

Babor, T.F., Higgins-Biddle, J.C., Saunders, J.B., Monteiro, M.G. (Eds.), 2001. AUDIT-The Alcohol Use Disorders Identification Test: Guidelines for Use in Primary Health Care, 2nd ed. World Health Organisation, Geneva.

Boschloo, L., Vogelzangs, N., Smit, J.H., van den Brink, W., Veltman, D.J., Beekman, A.T., Penninx, B.W., 2010. The performance of the Alcohol Use Disorder Identification Test (AUDIT) in detecting alcohol abuse and dependence in a population of depressed or anxious persons. J. Affect Disord. 126, 441-446.

Bowring, A.L., Gouillou, M., Hellard, M., Dietze, P., 2013. Comparing short versions of the AUDIT in a community-based survey of young people. BMC Public Health 13, 301. http://dx.doi.org/10.1186/1471-2458-13-301.

Bush, K., Kivlahan, D.R., McDonell, M.B., Fihn, S.D., Bradley, K.A., 1998. The AUDIT alcohol consumption questions (AUDIT-C): an effective brief screening test for problem drinking. Ambulatory Care Quality Improvement Project (ACQUIP). Alcohol Use Disorders Identification Test. Arch. Intern. Med. 158, 1789-1795.

Cantor, S.B., Sun, C.C., Tortolero-Luna, G., Richards-Kortum, R., Follen, M., 1999. A comparison of C/B ratios from studies using receiver operating characteristic curve analysis. J. Clin. Epidemiol. 52, 885-892.

Chung, T., Colby, S.M., Barnett, N.P., Monti, P.M., 2002. Alcohol use disorders identification test: factor structure in an adolescent emergency department sample. Alcohol. Clin. Exp. Res. 26, 223-231.

Chung, T., Colby, S.M., Barnett, N.P., Rohsenow, D.J., Spirito, A., Monti, P.M., 2000. Screening adolescents for problem drinking: performance of brief screens against DSM-IV alcohol diagnoses. J. Stud. Alcohol 61, 579-587.

W.J, Conover (Ed.), 1999. Practical Nonparametric Statistics, 3rd ed. John Wiley and Sons, Inc., New York.

Cook, R.L., Chung, T., Kelly, T.M., Clark, D.B., 2005. Alcohol screening in young persons attending a sexually transmitted disease clinic. Comparison of AUDIT, CRAFFT, and CAGE instruments. J. Gen. Intern. Med. 20, 1-6.

Cortes-Tomas, M.T., Gimenez-Costa, J.A., Motos-Selles, P., Sancerni-Beitia, M.D., 2016. Different versions of the Alcohol Use Disorders Identification Test (AUDIT) as screening instruments for underage binge drinking. Drug Alcohol Depend. 158, 52-59.

Costello, E.J., Sung, M., Worthman, C., Angold, A., 2007. Pubertal maturation and the development of alcohol use and abuse. Drug Alcohol Depend. 88 (Suppl. 1), 50-59.

Dawson, D.A., Grant, B.F., Stinson, F.S., 2005. The AUDIT-C: screening for alcohol use disorders and risk drinking in the presence of other psychiatric disorders. Compr Psychiatry 46, 405-416.

Dawson, D.A., Goldstein, R.B., Chou, S.P., Ruan, W.J., Grant, B.F., 2008. Age at first drink and the first incidence of adult-onset DSM-IV alcohol use disorders. Alcohol. Clin. Exp. Res. (32), 2149-2160.

DeLong, E.R., DeLong, D.M., Clarke-Pearson, D.L., 1988. Comparing the areas under two or more correlated receiver operating characteristic curves: a nonparametric approach. Biometrics 44, 837-845.

Demartini, K.S., Carey, K.B., 2012. Optimizing the use of the AUDIT for alcohol screening in college students. Psychol. Assess. 24, 954-963.

Doyle, S.R., Donovan, D.M., Kivlahan, D.R., 2007. The factor structure of the Alcohol Use Disorders Identification Test (AUDIT). J. Stud. Alcohol Drugs 68, 474-479.

Fairlie, A.M., Sindelar, H.A., Eaton, C.A., Spirito, A., 2006. Utility of the AUDIT for screening adolescents for problematic alcohol use in the emergency department. Int. J. Adolesc. Med. Health 18, 115-122.

Faraggi, D., Reiser, B., 2002. Estimation of the area under the ROC curve. Stat. Med. 21 
3093-3106

Foxcroft, D.R., Smith, L.A., Thomas, H., Howcutt, S., 2015. Accuracy of Alcohol Use Disorders Identification Test for detecting problem drinking in 18-35 year-olds in England: method comparison study. Alcohol Alcohol. 50, 244-250.

García Carretero, M.A., Novalbos Ruiz, J.P., Delgado, J.M., González, C.O., 2016. Validation of the Alcohol Use Disorders Identification Test in university students: AUDIT and AUDIT-C. Adicciones 28.

Harris, S.K., Knight, J.R., 2014. Putting the screen in screening: Technology-based alcohol screening and brief interventions in medical settings. Alcohol Res. 36, 63-79.

Hingson, R., Compton, W.M., 2014. Screening and brief intervention and referral to treatment for drug use in primary care: back to the drawing board. JAMA 312, 488-489.

Hingson, R.W., Zha, W., 2009. Age of drinking onset, alcohol use disorders, frequent heavy drinking, and unintentionally injuring oneself and others after drinking. Pediatrics 123, 1477-1484.

Irwin, R.J., 2009. Equivalence of the statistics for replicability and area under the ROC curve. Br. J. Math. Stat. Psychol. 62, 485-487.

Irwin, R.J., Irwin, T.C., 2011. A principled approach to setting optimal diagnostic thresholds: where ROC and indifference curves meet. Eur. J. Intern. Med. 22, 230-234.

Karlsson, L., Pelkonen, M., Ruuttu, T., Kiviruusu, O., Heila, H., Holi, M., Kettunen, K., Tuisku, V., Tuulio-Henriksson, A., Torronen, J., Marttunen, M., 2006. Current comorbidity among consecutive adolescent psychiatric outpatients with DSM-IV mood disorders. Eur. Child Adolesc. Psychiatry 15, 220-231.

Kaufman, J., Birmaher, B., Brent, D., Rao, U., Flynn, C., Moreci, P., Williamson, D., Ryan, N., 1997. Schedule for affective disorders and schizophrenia for school-age childrenpresent and lifetime version (K-SADS-PL): initial reliability and validity data. J. Am. Acad. Child Adolesc. Psychiatry 36, 980-988.

Kelly, T.M., Donovan, J.E., Chung, T., Bukstein, O.G., Cornelius, J.R., 2009. Brief screens for detecting alcohol use disorder among 18-20 year old young adults in emergency departments: comparing AUDIT-C, CRAFFT, RAPS4-QF, FAST, RUFT-Cut, and DSMIV 2-Item Scale. Addict. Behav. 34, 668-674.

Kelly, T.M., Donovan, J.E., Chung, T., Cook, R.L., Delbridge, T.R., 2004. Alcohol use disorders among emergency department-treated older adolescents: a new brief screen (RUFT-Cut) using the AUDIT, CAGE, CRAFFT, and RAPS-QF. Alcohol. Clin. Exp. Res. $28,746-753$.

Kelly, T.M., Donovan, J.E., Kinnane, J.M., Taylor, D.M., 2002. A comparison of alcoho screening instruments among under-aged drinkers treated in emergency departments. Alcohol Alcohol. 37, 444-450.

Knight, J.R., Sherritt, L., Harris, S.K., Gates, E.C., Chang, G., 2003. Validity of brief alcohol screening tests among adolescents: a comparison of the AUDIT, POSIT, CAGE, and CRAFFT. Alcohol. Clin. Exp. Res. 27, 67-73.

Kokotailo, P.K., Egan, J., Gangnon, R., Brown, D., Mundt, M., Fleming, M., 2004. Validity of the alcohol use disorders identification test in college students. Alcohol. Clin. Exp. Res. 28, 914-920.

Kriston, L., Holzel, L., Weiser, A.K., Berner, M.M., Harter, M., 2008. Meta-analysis: are 3 questions enough to detect unhealthy alcohol use? Ann. Intern. Med. 149, 879-888.

Kwon, U.S., Kim, J.S., Kim, S.S., Jung, J.G., Yoon, S.J., Kim, S.G., 2013. Utility of the alcohol consumption questions in the Alcohol Use Disorders Identification Test for screening at-risk drinking and alcohol use disorders among Korean college students. Korean J. Fam. Med. 34, 272-280.

Li, D.L., Shen, F., Yin, Y., Peng, J.X., Chen, P.Y., 2013. Weighted Youden index and its two-independent-sample comparison based on weighted sensitivity and specificity. Chin. Med. J. (Engl.) 126, 1150-1154.

Lintonen, T., Karlsson, T., Nevalainen, J., Konu, A., 2013. Alcohol policy changes and trends in adolescent drinking in Finland from 1981 to 2011. Alcohol Alcohol. 48, 620-626.

Masten, A.S., Faden, V.B., Zucker, R.A., Spear, L.P., 2008. Underage drinking: a developmental framework. Pediatrics 121 (Suppl. 4), S235-S251.
McCambridge, J., Thomas, B.A., 2009. Short forms of the AUDIT in a Web-based study of young drinkers. Drug Alcohol Rev. 28, 18-24.

Meneses-Gaya, C., Zuardi, A.W., Loureiro, S.R., Hallak, J.E., Trzesniak, C., de Azevedo Marques, J.M., Machado-de-Sousa, J.P., Chagas, M.H., Souza, R.M., Crippa, J.A., 2010. Is the full version of the AUDIT really necessary? Study of the validity and internal construct of its abbreviated versions. Alcohol Clin. Exp. Res. 34, 1417-1424.

O'Hare, T., Sherrer, M.V., 1999. Validating the Alcohol Use Disorder Identification Test with college first-offenders. J. Subst. Abuse Treat. 17, 113-119.

Palma, F.S., Manríquez, G.S., Barriga, O.A., 2013. Validity and reliability of the Alcohol Use Disorders Identification Test of Disorders (AUDIT) in students of a Chilean University. Sci. Nurs. 19, 23-35.

Patton, R., Deluca, P., Kaner, E., Newbury-Birch, D., Phillips, T., Drummond, C., 2014. Alcohol screening and brief intervention for adolescents: the how, what and where of reducing alcohol consumption and related harm among young people. Alcohol Alcohol. 49, 207-212.

Patton, R., Boniface, S., 2016. Prevalence of Hazardous Drinking Among UK 18-35 Year Olds; the Impact of a Revision to the AUDIT Cut Score. Alcohol Alcohol 51, 281-282.

Pilowsky, D.J., Wu, L.T., 2013. Screening instruments for substance use and brief interventions targeting adolescents in primary care: a literature review. Addict. Behav. 38, 2146-2153.

Pirkola, S.P., Isometsa, E., Suvisaari, J., Aro, H., Joukamaa, M., Poikolainen, K., Koskinen, S., Aromaa, A., Lonnqvist, J.K., 2000. DSM-IV mood-, anxiety- and alcohol use disorders and their comorbidity in the Finnish general population-results from the Health Study. Soc Psychiatry Psychiatr Epidemiol. 40, 1-10.

Reinert, D.F., Allen, J.P., 2002. The Alcohol Use Disorders Identification Test (AUDIT): a review of recent research. Alcohol. Clin. Exp. Res. 26, 272-279.

Reinert, D.F., Allen, J.P., 2007. The alcohol use disorders identification test: an update of research findings. Alcohol. Clin. Exp. Res. 31, 185-199.

Rumpf, H.J., Wohlert, T., Freyer-Adam, J., Grothues, J., Bischof, G., 2013. Screening questionnaires for problem drinking in adolescents: performance of AUDIT, AUDIT-C, CRAFFT and POSIT. Eur. Addict. Res. 19, 121-127.

Santis, R., Garmendia, M.L., Acuna, G., Alvarado, M.E., Arteaga, O., 2009. The Alcohol Use Disorders Identification Test (AUDIT) as a screening instrument for adolescents. Drug Alcohol Depend. 103, 155-158.

Saunders, J.B., Aasland, O.G., Babor, T.F., de la Fuente, J.R., Grant, M., 1993. Development of the Alcohol Use Disorders Identification Test (AUDIT): WHO collaborative project on early detection of persons with harmful alcohol consumption-II. Addiction 88, 791-804.

Sihvola, E., Rose, R.J., Dick, D.M., Pulkkinen, L., Marttunen, M., Kaprio, J., 2008. Earlyonset depressive disorders predict the use of addictive substances in adolescence: a prospective study of adolescent Finnish twins. Addiction 103, 2045-2053.

Smits, N., 2010. A note on Youden's J and its cost ratio. BMC Med. Res. Methodol. 1089 2288-10-89.

Thomas, B.A., McCambridge, J., 2008. Comparative psychometric study of a range of hazardous drinking measures administered online in a youth population. Drug Alcohol Depend. 96, 121-127.

von der Pahlen, B., Santtila, P., Witting, K., Varjonen, M., Jern, P., Johansson, A., Sandnabba, N.K., 2008. Factor structure of the Alcohol Use Disorders Identification Test (AUDIT) for men and women in different age groups. J. Stud. Alcohol Drugs 69, 616-621.

Winters, K.C., Lee, C.Y., 2008. Likelihood of developing an alcohol and cannabis use disorder during youth: association with recent use and age. Drug Alcohol Depend. 92, 239-247.

Youden, W.J., 1950. Index for rating diagnostic tests. Cancer 3, 32-35.

Zeigler, D.W., Wang, C.C., Yoast, R.A., Dickinson, B.D., McCaffree, M.A., Robinowitz, C.B., Sterling, M.L., Council on Scientific Affairs, American Medical Association, 2005. The neurocognitive effects of alcohol on adolescents and college students. Prev. Med, 40, 23-32. 